\title{
FILOSOFIA NO ENSINO MÉDIO: SOBRE COMO OS CONHECIMENTOS FILOSÓFICOS PODEM CONTRIBUIR PARA O EXERCÍCIO DA CIDADANIA
}

Valdson dos Remédios Silva Amorim ${ }^{1}$ Jonh Elvis Costa Martins ${ }^{2}$

Resumo: Este trabalho compõe-se de algumas reflexões sobre o ensino de filosofia na educação básica brasileira. Especificamente, analisar-se-ão dois pontos relativos à atividade filosófica na educação básica, a saber: 1) o ensino de filosofia concebido como exercício de pensamento, de modo a reivindicar, a partir da prática filosófica, um filosofar na educação; 2) as contribuições que a filosofia pode oferecer para a formação do aluno do ensino médio, sobretudo no que diz respeito ao exercício da cidadania. Esses dois pontos serão analisados na perspectiva de reforçar a importância da filosofia como componente curricular obrigatório e como instrumento imprescindível para que sejam alcançados os objetivos do ensino médio, última etapa da educação básica, entendida esta como instrumento que prepara o indivíduo para exercer o seu papel de cidadão.

Palavras-chave: Filosofia; Ensino Médio; Cidadania; Educação Básica.

\begin{abstract}
This essay is composed of some thoughts about the teaching of philosophy at the basic Brazilian education. Two points related to the philosophical activity will be analyzed, specifically. These being: 1) the teaching of philosophy conceived as a thinking exercise, to claim, from a philosophical practice, to philosophize on education; 2) the benefits that philosophy may offer to the high school student's, specially regarding the citizenship activity. Both these points will be analyzed considering the perspective of reinforcing the importance as a mandatory curricular component and as an indispensable instrument the achievement of high school's educational goals, last stage of basic education, that being understood as fundamental to a man exercise of its own citizenship.
\end{abstract}

Keywords: Philosophy; High School; Citizenship; Basic Education.

\footnotetext{
${ }^{1}$ Mestrando em Ciências da Educação pela "Universidad de la Empresa" - UDE, em Montevidéu/Uruguai. PósGraduado em Metodologia do Ensino Superior pela FAEL (Faculdade Educacional da Lapa). Graduado em Filosofia - Licenciatura Plena, pela FPA (Faculdade Pan Americana). Graduado em Letras Língua Portuguesa e Língua Inglesa, pela Universidade Anhanguera-UNIDERP. Professor de Filosofia da rede pública do estado Pará.

${ }^{2}$ Graduado em Filosofia - Licenciatura Plena, pela FPA (Faculdade Pan Americana).
} 


\section{Introdução}

A filosofia foi reintroduzida na educação básica brasileira, como componente curricular obrigatório, em 2008, através da Lei $\mathrm{n}^{\mathrm{o}}$ 11.684/08, que alterou o art. 36 da LDB, Lei $n^{\circ}$ 9.394/96, que estabelece as Diretrizes e Bases da Educação Nacional. Desde sua reinserção, falar de filosofia no ensino médio brasileiro tem representado um desafio, uma vez que somos sempre incitados a justificar as razões que a mantêm com o status de disciplina obrigatória do currículo.

Não obstante, em que pese essa necessidade, o objetivo deste trabalho não é defender a filosofia enquanto componente curricular, mas reforçar a importância dessa disciplina como parte do conjunto de saberes que compõem o currículo da educação básica, especialmente no tocante a dois pontos principais. Em primeiro lugar, será abordado o ensino de filosofia no nível médio como uma prática de pensamento, como um Filosofar no âmbito da educação básica. Em segundo lugar, concebido o ensino de filosofia como prática filosófica na educação, analisar-se-á em que medida essa prática pode colaborar para que a educação básica alcance seus objetivos pautados na legislação educacional do país, especificamente, no que diz respeito ao exercício da cidadania.

Essa relação entre ensino de filosofia e as finalidades da educação cobra relevância na medida em que se considere que a realidade educativa é também objeto de reflexão filosófica e que, por conseguinte, subaz a todo processo educativo uma filosofia, neste caso específico, uma filosofia da educação. Portanto, ensinar filosofia na educação básica pressupõe, de certa forma, refletir sobre a realidade educacional enquanto processo de formação do homem, dimensão sobre a qual a filosofia também tem um interesse especial.

Partindo desses pressupostos, serão analisadas as duas questões postas anteriormente na perspectiva de reforçar a ideia de que a filosofia, enquanto componente curricular da educação básica, da qual o ensino médio constitui a última etapa, cumpre uma função importantíssima na formação humana e cidadã do educando, porquanto que o exercício da cidadania exige que o indivíduo tenha certa capacidade de discernimento sobre o seu papel na sociedade.

\section{O ensino de filosofia como prática de pensamento: por um filosofar na educação}

A filosofia pode ser caracterizada de várias maneiras, a depender da época, do contexto e até da concepção de mundo de quem toma para si a tarefa de defini-la. Para situar 
este trabalho numa perspectiva a partir da qual a filosofia pode ser abordada, será tomada como referência a ideia segundo a qual "a filosofia é uma prática discursiva razoável (de preferência 'racional'...)". (COMTE-SPONVILLE, 2005, p. 10).

Essa prática discursiva pressupõe que quem a realize faça uso da razão, e a partir desse raciocínio pode-se inferir que há uma relação inquebrantável entre a filosofia e sua prática, o filosofar. Urge, no entanto, buscar compreender qual o contributo da filosofia para a formação do aluno do ensino médio, considerando não somente a relação do educando com as complexidades da realidade presente, mas, sobretudo, numa perspectiva de futuro.

Desse ponto de vista, a filosofia a ser trabalhada nas aulas da educação básica não se equipara a uma disciplina morta, indiferente à realidade do educando; ao contrário, "é uma filosofia interessada em transformar o mundo existente, para pensar de forma explícita e declarada as contribuições do filosofar para uma realidade que pede transformações aos gritos”. (KOHAN, 1998, p. 93).

Essas transformações às quais o autor faz referência serão possíveis na medida em que os indivíduos tomem consciência do seu papel como agentes ativos na sociedade. E para que isso aconteça, a filosofia pode dar uma importante contribuição se o trabalho com a disciplina no ensino médio se constituir numa prática reflexiva; se a filosofia for pensada e trabalhada como uma prática filosofante, como um filosofar.

Há de se ter em conta, no entanto, que o trabalho com a filosofia se insere no âmbito da problemática educacional, e é diante dessa problemática que se faz necessária uma atitude filosófica, uma postura reflexiva que permita o entendimento da realidade educativa em suas variadas manifestações.

Essa atitude implica a problematização da realidade e se afirma como prática eminentemente filosófica. Portanto, o trabalho com filosofia no âmbito da educação básica não só supõe uma relação com os conhecimentos filosóficos, mas, ao mesmo tempo, uma prática do filosofar na educação. Essa ideia remete à noção de filosofia da educação, concebida como uma reflexão acerca da atividade educativa.

Assim sendo, o ensino de filosofia pressupõe a orientação do educando para a prática do pensamento crítico e reflexivo. É a partir dessa atitude que poderão ser realizadas as transformações na sociedade das quais o educando de hoje será, ou até já é, protagonista. É nesse sentido que, de acordo com as Diretrizes Curriculares Nacionais, "a educação constitui importante estratégia de transformação, uma vez que a inclusão na sociedade contemporânea 
não se dá sem o domínio de determinados conhecimentos que devem ser assegurados a todos". (BRASIL, 2013, p. 167).

Desse modo, com a perspectiva de um grande contingente de jovens inseridos em uma sociedade carente de mudança e que, por tanto, podem se credenciar para realizá-las é que o trabalho filosófico na educação básica deve ser desenvolvido. A filosofia, nesse contexto, embora não dê conta, por si só, de realizar todas as mudanças que a realidade demanda, pode, sem dúvida, proporcionar condições que ampliem as possibilidades para que os educandos as realizem.

O ensino de filosofia no nível médio adquire maior valor na medida em que pode efetivar-se como uma prática, mas também como ferramenta para as ações futuras dos estudantes, o que equivale dizer que o ensino de filosofia é uma prática que inspira outras práticas. É nesse sentido que a filosofia deve ser trabalhada em sala de aula no ensino médio: como uma atividade prática, reflexiva; como um filosofar.

Por isso, vale dizer que tanto quanto ensinar filosofia é urgente a necessidade de praticá-la no âmbito da educação básica, até porque filosofia e filosofar não são duas coisas dissociadas, mas termos que exprimem duas particularidades de uma coisa só. A filosofia pode ser caracterizada, nesse sentido, como "uma prática teórica porquanto essa prática se sustenta sobre fundamentos teóricos que legitimam seu desenvolvimento". (KOHAN, 1998, p. 99).

Essa prática teórica, que pode ser concebida como exercício filosófico propriamente dito, deve ser pensada como uma atividade que proporcione aos estudantes condições para que estes pensem a realidade na perspectiva da produção de sentido, da compreensão das complexidades do mundo e de sua própria existência. A isso se chama filosofar na educação.

Essa ideia de filosofar no âmbito da educação suscita e exige uma série de atitudes tanto por parte dos alunos quanto dos professores, entre elas, certa disposição para o questionamento das verdades estabelecidas, dos valores tidos como inamovíveis. Isto não seria uma novidade para a filosofia, porque constitui um dos pressupostos para que a atividade filosófica aconteça.

Colocar em questão não pressupõe, nessa análise, contar com as condições para solucionar os problemas. Vale dizer, por conseguinte, que o filosofar se insere justamente no centro dessa dificuldade, haja vista que uma das características de um problema filosófico é a nossa "impossibilidade de resolvê-lo com os conhecimentos e procedimentos que num determinado momento histórico conhecemos e dominamos”. (PALÁCIOS, 2007, p. 82). 
Mas essa impossibilidade não deve limitar o exercício filosófico, porque assim como as respostas aos problemas filosóficos se recobrem de importância para a atividade filosófica, a formulação dos problemas, de igual modo, constitui elemento sem o qual essa atividade não seria filosófica propriamente, em sentido estrito.

Nessa perspectiva, convém dizer, a modo de esclarecimento, que

a filosofia não cria suas questões; apenas oferece uma lógica às questões presentes
no mundo, isto é, os valores, práticas, ideias, conceitos, verdades, fins que a filosofia
pensa não emanam da própria filosofia, mas do mundo existente. A filosofia os
ordena de certa maneira, os reconfigura, os traduz a outros códigos e outras
categorias, os mostra de outras formas. (KOHAN, 1998, p. 106).

Nesse sentido, filosofar na educação significa refletir sobre a realidade em geral, mas, de forma específica, sobre a realidade da atividade educativa, numa perspectiva problematizadora, o que equivale a dizer que à filosofia compete apresentar de forma mais complexa as questões presentes no mundo, não por mero gosto pela complexidade, mas para buscar esclarecer as peculiaridades da realidade que por ventura precisem de uma análise mais aprofundada. E essa análise aprofundada, crítica e reflexiva é uma das características da atividade filosófica.

Filosofar na educação significa, então, problematizar a realidade educativa para encontrar um sentido, um significado, um fundamento. É, por conseguinte, tarefa da filosofia proporcionar as condições para que o educando desenvolva essas potencialidades; e para que essa atribuição da filosofia seja levada a êxito, o professor da disciplina cumpre um papel fundamental como orientador do processo educacional.

Nessa linha, recordemos que um dos argumentos apresentados como justificativa para a volta da filosofia ao currículo do ensino médio foi o da necessidade do aluno, nessa etapa da educação básica, desenvolver a criticidade, sugerindo como objetivo do ensino médio "o aprimoramento do educando como pessoa humana, incluindo a formação ética e o desenvolvimento da autonomia intelectual e do pensamento crítico". (BRASIL, 2015, p. 24).

O desenvolvimento da criticidade pressupõe certa autonomia intelectual que lhe proporcione condições para estabelecer o diálogo e defender seus pontos de vista, o que requer algum grau experiência com a filosofia. Na busca dessa liberdade de pensamento, "as práticas pedagógicas no âmbito do ensino de filosofia têm privilegiado três aspectos balizadores da prática filosófica: problematizar um tema; conceituar uma noção; argumentar sobre uma tese". (RODRIGO, 2007, p. 44). 
Esses três aspectos estão em consonância com a atividade filosófica, entendida como processo através do qual o educando adquire as ferramentas para pensar filosoficamente a realidade numa atitude problematizadora. Essa capacidade de problematização "implica a assunção de uma postura filosófica diante do real”. (Ibid., p. 44). Essa é a questão à qual a filosofia se propõe a dar uma resposta adequada, ainda que não definitiva.

Por isso, a incumbência da filosofia como componente curricular do ensino médio não é pequena e nem fácil, porque implica um trabalho de orientação para que o aluno se distancie das opiniões com as quais conviveu a vida toda. Não significa abandonar suas opiniões, suas verdades, seus valores, mas repensá-los de modo significativo, e isso o levará a uma nova concepção da realidade e da vida, diferente, talvez, daquela visão comum de mundo que possuía anteriormente.

Desse modo, justifica-se a concepção de filosofia segundo a qual "ela é uma luta, principalmente contra a própria ignorância”. (PALÁCIOS, 2007, p. 82). Nesse sentido, a tarefa do aluno de filosofia seria buscar entender os aspectos mais complexos da realidade em geral e, particularmente, da realidade educacional.

Filosofar na educação é sinônimo, nesse caso, de pensar sobre a realidade educativa; "é buscar uma maneira de entender o que a primeira vista parece incompreensível, mas não o é; uma forma de clarificar o que é visto como obscuro ou confuso". (KOHAN, 1998, p. 109). Por isso, a filosofia no ensino médio deve ser entendida como uma prática de busca da verdade cujo pressuposto é a disposição para a reflexão, para o diálogo aberto com as outras áreas do saber.

Assim, a filosofia no ensino médio não só é possível, mas imprescindível, porque há necessidade de conhecimentos que capacitem os alunos para a resistência ao dogmatismo, à ignorância, ao doutrinamento. E há de se fazer dessa resistência uma prática educativa que se oponha à ideia de verdades inquestionáveis, a fim de dar novos significados à realidade e que desperte no educando a inquietação diante do que se lhes apresenta como valores estabelecidos.

Essa dimensão do filosofar na educação constitui uma tentativa de fazer que as práticas educativas se convertam em práticas de reflexão, com vistas ao descobrimento não daquilo que o mundo é, mas daquilo que poderá vir a ser; em práticas de reflexão acerca da realidade educativa e do próprio indivíduo como sujeito ativo dessa prática. Filosofar na educação, nesse sentido, significa trabalhar para que se construa uma lógica diferente para o modo de ver o mundo e a si próprio como sujeito nesse mundo. Filosofar na educação é, em 
última instância, fazer filosofia no âmbito da educação. E é para isso que devem servir as aulas de filosofia no ensino médio brasileiro, porque na medida em que o aluno se aproprie dessas ferramentas ele estará mais apto para exercer o seu papel de cidadão numa sociedade cuja dinamicidade desafia o indivíduo dia-a-dia.

\section{A contribuição do ensino de filosofia para o exercício da cidadania}

Seguindo o raciocínio com que se concluiu o tópico anterior, vale assinalar que a legislação educacional brasileira concebe a filosofia como instrumento de formação dos indivíduos para o exercício da cidadania. Essa é a principal justificativa que fundamenta sua presença no currículo da Educação Básica do país. (BRASIL, 2010, p. 185). Mas o que é que o estado espera, realmente, da filosofia quando atribui a ela essa responsabilidade? O que é que se entende por cidadania para cujo exercício a filosofia seria um instrumento de formação? Quais seriam esses conhecimentos filosóficos aos quais a LDB faz referência e que ao serem apropriados pelos alunos os capacitariam para o exercício da cidadania?

O termo "cidadania", como se sabe, é muito amplo e pode adquirir significados diversos a depender do contexto em que é empregado. Nesse sentido, a concepção que se tenha de sociedade pode determinar o que se entende por cidadania ou por cidadão. Assim, para os gregos antigos, cidadãos eram os indivíduos que pertenciam a uma comunidade. No entanto, para se adquirir o status de cidadão não era requisito suficiente a pertença a determinada comunidade ou espaço geográfico.

Segundo Aristóteles, na obra A política, "o cidadão não é cidadão porque vive em um certo lugar, pois os estrangeiros e os escravos também são estabelecidos em um lugar”. (ARISTÓTELES, 2001, p. 113). Isso nos leva a inferir que nem todos os indivíduos pertencentes a uma determinada sociedade são cidadãos, de acordo com a concepção aristotélica. Desta categoria ficam excluídos os estrangeiros e os escravos, entre outros. Então, quem são os cidadãos nesse contexto?

Por cidadão entende Aristóteles "aquele que tem o poder de tomar parte na administração deliberativa ou judicial de alguma cidade”. (ibid., p. 115). Dessa forma, a cidadania não é um atributo de todos os indivíduos, mas daqueles que, além de pertencerem à comunidade, contam com os meios suficientes para levar uma vida livre. Esses meios são, preferencialmente, bens tais como terra, casa e, inclusive, escravos.

Em última análise, cidadãos são os indivíduos que possuem alguma riqueza. Esses são os que têm o direito de se manifestar livremente acerca dos assuntos relativos à comunidade. 
Nessa perspectiva, a filosofia poderia ser concebida como um instrumento imprescindível para a formação dos indivíduos com vistas ao adequado exercício da cidadania, entendida esta como direito de participação nas deliberações de modo geral, posto que, na Grécia antiga, exercer a cidadania equivaleria a fazer uso da palavra nas assembleias, o que requer certa capacidade de argumentação e o exercício do pensamento crítico.

Mas o conceito de cidadania, tal como entendido na atualidade, tem o mesmo significado e extensão que tinha naquela realidade da Grécia antiga? O que se entende hoje quando lemos que a finalidade da educação nacional é a preparação do individuo para o exercício da cidadania?

A Constituição Federal de 1988, ao definir, em seu artigo primeiro, o Brasil como um Estado Democrático de Direito, concebe a cidadania como um de seus fundamentos. (BRASIL, 2016, p. 5). Embora o texto da Constituição não defina o que é cidadania, é possível inferir que se trata da cidadania entendida como condição de possibilidade para o exercício de direitos e obrigações.

Esses direitos e deveres, constantes em diversos artigos da Constituição e comuns a todos os cidadãos são:

a vida, a liberdade, a igualdade, a segurança, a propriedade; a educação, a saúde, a alimentação, o trabalho, a moradia, o lazer, a segurança, a previdência social, a proteção à maternidade e à infância, a assistência aos desamparados; a soberania popular, o sufrágio universal, o voto direto e secreto. (BRASIL, 2016, Arts. $5^{\circ}, 6^{\circ}$ e $14)$.

Esse é o sentido atribuído à cidadania quando a própria Constituição, em seu artigo 205, concebe a educação como um direito cuja finalidade é "o pleno desenvolvimento da pessoa, seu preparo para o exercício da cidadania e sua qualificação para o trabalho”. (Ibid. p. 43). Daí é possível derivar que a educação constitui um instrumento importante para que o aluno se conscientize de seus deveres e seus direitos enquanto cidadão, de modo que esteja capacitado para cumprir com responsabilidade suas obrigações, ao mesmo tempo em que possa reivindicar conscientemente proteção e respeito aos seus direitos.

Essa finalidade da educação, estabelecida na Constituição, é confirmada pela LDB, Lei ${ }^{\circ}$ 9.394/96, em seu artigo $2^{\circ}$, nos termos seguintes: “a educação [...] tem por finalidade o pleno desenvolvimento do educando, seu preparo para o exercício da cidadania e sua qualificação para o trabalho”. (BRASIL, 2015, p. 9). Dessa forma, o exercício da cidadania exige uma formação que proporcione aos alunos condições para que estes se desenvolvam em suas várias dimensões na sociedade. 
Para que essa formação aconteça, a LDB estabelece, em seu artigo 36, inciso III, alguns conteúdos indispensáveis para serem trabalhados em sala de aula, entre os quais constam os conteúdos de filosofia e sociologia como disciplinas obrigatórias em todas as séries do ensino médio. (Ibid., p. 25).

Partindo desse pressuposto, pode-se considerar que a filosofia, enquanto disciplina cuja tarefa é proporcionar ao educando condições para que seja capaz de pensar reflexivamente a realidade, adquirindo, por conseguinte, consciência plena de seus direitos e deveres, pode contribuir, efetivamente, para que este exerça, de forma consciente, seu papel de cidadão na sociedade, tal como a legislação educacional sugere.

Se para que o aluno adquira consciência de seus direitos e deveres é necessária certa maturidade intelectual, entendida como capacidade de pensar reflexiva e autonomamente, então a filosofia pode responder a essa demanda e, consequentemente, contribuir para que a educação cumpra sua finalidade haja vista que essa é justamente a atribuição outorgada à filosofia na LDB.

Partindo desse entendimento, a filosofia, junto com as outras disciplinas, deve contribuir para que os objetivos do ensino médio sejam alcançados; entre esses objetivos, o que está colocado no artigo 35, inciso II da LDB e que faz referência ao "aprimoramento do educando como pessoa humana, incluindo a formação ética e o desenvolvimento da autonomia intelectual e do pensamento crítico". (Ibid., p. 24).

O exercício da criticidade, cujo desenvolvimento é comumente atribuído à filosofia, faz-se imprescindível ao indivíduo que vive numa sociedade que lhe exige, constantemente, capacidade de escolha. E essas escolhas influenciarão o modo como ele exercerá sua cidadania, considerando que a importância dada aos direitos e aos deveres individuais numa sociedade democrática está relacionada com a forma como se concebe a realidade. E nesse aspecto a filosofia pode dar uma contribuição significativa. Por isso, defender a ausência da filosofia como componente curricular do ensino médio equivale, sem dúvida, a eliminar do currículo um conjunto de conhecimentos possíveis e imprescindíveis para que o educando se forme enquanto cidadão consciente de seus direitos e atribuições.

Com base nos postulados constantes da legislação sobre a relação entre a filosofia e o desempenho do indivíduo no desenvolvimento de seu papel de cidadão, onde está assegurado que uma das finalidades da educação básica é o preparo para a cidadania cujo exercício exige, necessariamente, que o educando tenha domínio de conhecimentos filosóficos, pode-se inferir que o domínio desses conhecimentos é condição necessária para o que indivíduo exerça sua 
cidadania e, dessa forma, reconheça a si mesmo como sujeito portador de direitos fundamentais.

Partindo desse pressuposto, e considerando que a filosofia é componente curricular obrigatório da educação básica, conclui-se que o seu aporte para a formação do aluno do ensino médio é inquestionável.

Nessa perspectiva, a filosofia se apresenta como condição para que a educação alcance seus objetivos, de modo especial aqueles relacionados com a formação do cidadão, considerando, para tanto, que o exercício da cidadania exige uma compreensão ampla da realidade, o que pressupõe que o indivíduo tenha consciência de seus direitos e atribuições, de modo que seja capaz de exercer uma postura crítica e reflexiva sobre o mundo e sobre sua própria existência no mundo.

O desenvolvimento dessa atitude reflexiva é uma das contribuições que a filosofia pode oferecer para a formação do aluno do ensino médio, posto que "a especificidade da atividade filosófica consiste, em primeiro lugar, em sua natureza reflexiva”. (BRASIL, 1999, p. 47). Desse ponto de vista, o exercício da cidadania pressupõe uma compreensão acerca de seus fundamentos, especialmente nos termos do que sugere o texto constitucional, a saber: a cidadania como condição para o exercício dos direitos fundamentais.

Agora bem, dizer que a filosofia pode formar o educando para o exercício da cidadania, tal como apregoa a legislação, não significa que a filosofia dará conta de responder, sozinha, a essa demanda. A formação cidadã não é um processo que dura o tempo de um curso de filosofia. Nem a filosofia pode pretender resolver todas as peculiaridades relativas à formação de um cidadão numa sociedade como a contemporânea, cuja característica principal é a mudança, a transformação, onde o indivíduo sente a necessidade constante de se reinventar e atualizar seus saberes.

A filosofia não se furtará à responsabilidade de promover condições para que o educando desenvolva o pensamento reflexivo e, por conseguinte, esteja em condições de melhor exercer suas funções e defender seus direitos enquanto cidadão. Não obstante, sua contribuição deve ser inserida dentro do conjunto de contribuições das outras áreas do saber, haja vista que essa atribuição não é sua com exclusividade, mas da educação como um todo.

Qual seria, então, a contribuição específica da filosofia para a formação cidadã do educando nessa etapa de sua formação? A resposta consta do texto das Orientações Curriculares Nacionais nos seguintes termos: 


\section{REVISTA APOENA - Per. dos Dis. de Fil. da UFPA \\ Belém, 2019, V. 1, N.1.}

cabe, então, especificamente à filosofia a capacidade de análise, de reconstrução racional e de crítica, a partir da compreensão de que tomar posições diante de textos propostos de qualquer tipo (tanto textos filosóficos quanto textos não filosóficos e formações discursivas não explicitadas em textos) e emitir opiniões acerca deles é um pressuposto indispensável para o exercício da cidadania. (BRASIL, 2006, p. 26).

Uma vez que o educando se aproprie dos conhecimentos que lhe permitam desenvolver as habilidades presentes no fragmento citado, é provável que desempenhe bem o seu papel de cidadão. Não obstante, ainda reconhecendo que os conhecimentos de filosofia podem proporcionar condições para a formação cidadã, "seria criticável tentar justificar a Filosofia apenas por sua contribuição como instrumento de preparação para o exercício da cidadania". (Ibid., p. 25).

Assim, a atribuição outorgada à filosofia pela legislação é legítima, mas não limitadora de sua ação como componente formativo do educando do ensino médio. Muito mais importante do que limitar sua abrangência parece ser considerá-la como instrumento para a formação geral do indivíduo, no caso específico, os alunos da educação básica da qual o ensino médio constitui a última etapa.

Portanto, assim como o ensino de filosofia se apresenta hoje cheio de complexidades, o exercício da cidadania, para o qual os conhecimentos filosóficos configuram meios preparatórios recomendados na legislação, tampouco é uma matéria de simples compreensão. Se o exercício da cidadania pressupõe que o indivíduo tenha consciência de seus direitos e deveres e que, ademais, seja capaz de exercer os primeiros e cumprir os segundos de forma livre, a tarefa da filosofia na consecução dos objetivos da educação básica não é pequena nem fácil.

Assim, em que pese as dificuldades que poderiam, eventualmente, surgir como obstáculos ao trabalho com a filosofia, esta constitui um elemento sine qua non para que a educação leve a termo suas finalidades estabelecidas na legislação educacional brasileira, de forma específica, os objetivos de sua última etapa, o ensino médio.

\section{Considerações Finais}

A história da filosofia como disciplina do currículo da educação brasileira tem sido marcada por muitos desencontros. Desde seus inícios, no século XVI, até recentemente, o que se pode notar é que ela sempre enfrentou dificuldades para construir sua própria identidade como componente curricular. Essa situação tem reflexos, inegavelmente, em alguns aspectos relevantes para a atividade docente dos professores da disciplina na educação básica. 
Entre as tantas dificuldades que afetaram, e ainda afetam, o trabalho com a filosofia na escola brasileira, merece destaque a falta de um programa que estabeleça as diretrizes mínimas para a docência da disciplina no país, bem como os objetivos claramente definidos do trabalho com filosofia na escola.

Por essa razão, este trabalho se propôs a refletir sobre o ensino de filosofia na escola de educação básica brasileira, na perspectiva de concebê-la como instrumento de formação do indivíduo para o exercício da cidadania, entendendo cidadania como a consciência que o indivíduo tem de seus deveres e atribuições no âmbito da sociedade à qual pertence.

O objetivo do trabalho foi oferecer uma reflexão atual e contextualizada sobre a temática do ensino da filosofia como contributo para a formação do cidadão. Para tanto, partiu-se da concepção da filosofia como instrumento de formação cidadã, uma formação fundamentada sobre as bases da criticidade diante da realidade, que nos exige uma atitude reflexiva enquanto sujeitos ativos do processo de construção social, atribuindo à filosofia uma função eminentemente formadora.

Contudo, há de se reconhecer que para que a filosofia exerça sua função formadora, no contexto de um processo educacional que prepare para o exercício da cidadania, é necessário, ainda, muito esforço para que se logre a consolidação da sua presença e importância na educação básica do país. A consecução dessa tarefa exige muito mais do que dispositivos legais ou grandes discussões em torno da temática específica, inclusive no âmbito da própria escola, onde abundam boas intenções tanto dos professores quanto dos dirigentes e gestores educacionais.

É necessário que aos projetos pedagógicos das escolas subjaza um espírito filosófico propriamente dito. E vale dizer, nesse sentido, que o ensino de filosofia pode constituir um instrumento para repensar, discutir e analisar a realidade da própria atividade educativa em seu contexto social, e dentro dessa atividade, as atribuições da filosofia, suas funções e finalidades. Nessa perspectiva, a filosofia poderia ser entendida como uma prática discursiva, crítica e razoável sobre si mesma e sobre a realidade do processo formativo do aluno e do cidadão.

Como instrumento formativo, ela se insere no rol das disciplinas de humanidades e, como tal, deve contribuir para a formação do aluno na perspectiva do fortalecimento de suas potencialidades, especialmente no que tange ao desenvolvimento da criticidade, tarefa a ela atribuída pela legislação brasileira e que tem sido concebida como uma de suas características 
mais relevantes e um dos pilares sobre os quais se fundamenta a formação do indivíduo para uma adequada prática cidadã.

\section{REFERÊNCIAS BIBLIOGRÁFICAS}

ARISTÓTELES. A política. 6a . Edição. São Paulo: Martin Claret, 2001.

BRASIL. Lei de Diretrizes e Bases da Educação Nacional, Lei n 9.394/96. In: DAVIES, Nicolas. Legislação Educacional Federal Básica. 2ª Edição. São Paulo: Cortez, 2010.

Diretrizes Curriculares Nacionais da Educação Básica / Ministério da Educação. Secretaria de Educação Básica. Diretoria de Currículos e Educação Integral. Brasília: MEC, SEB, DICEI, 2013.

Legislação Brasileira sobre Educação. 3ª Edição. Brasília: Edições Câmara, 2015.

MEC/SEB. Orientações Curriculares para o Ensino Médio - Ciências Humanas e suas Tecnologias (Vol. 3). Brasília: Ministério da Educação/Secretaria de Educação Básica, 2006.

MEC/SEMT. Parâmetros Curriculares Nacionais para o Ensino Médio - Ciências Humanas e suas Tecnologias. Brasília: Ministério da Educação/Secretaria de Educação Média e Tecnológica, 1999.

Presidência da República. Casa Civil. Subchefia para Assuntos Jurídicos. Constituição da República Federativa do Brasil de 1988. Brasília, 2016.

COMTE-SPONVILLE, A. A Filosofia. São Paulo: Martins, 2005.

KOHAN, Walter O. Filosofía de la educación: a la busca de nuevos sentidos. In: Educação e Filosofia, vol. 12, nº 24, jul./dez. 1998.

PALÁCIOS, José G. A. Ensina-se filosofar, filosofando. In: Philósophos, vol. 12, $\mathrm{n}^{\mathrm{o}} 1$. Jan/jun. 2007, p. 79-90.

RODRIGO, Lidia Maria. Uma alternativa para o ensino de filosofia no nível médio. In: Filosofia no ensino médio: temas, problemas e propostas. SILVEIRA, R. J. T.; GOTO, Roberto (Orgs). São Paulo: Edições Loyola, 2007, p. 37-51. 